\title{
Model and Experimental Detection of Single Phase-to-Ground Fault for Overhead Wires in Distribution Networks by Location Method
}

\author{
Minullin Renat ${ }^{1, *}$, Piskovatsky Yuri ${ }^{1}$, and Kasimov Vasil ${ }^{1}$ \\ ${ }^{1}$ Kazan State Power Engineering University, 420066, 51 Krasnoselskaya str., Kazan, Russia
}

\begin{abstract}
The simulation model of the overhead transmission line channel implemented in PSCAD software allowing researches of location signal propagation via overhead lines of the distribution networks $6-35 \mathrm{kV}$ under conditions of single phase-to-ground fault is considered. The model reflectograms are compared with their appropriate experimental reflectograms registered under the laboratory and field conditions for the overhead lines during simulation of various types of the single phase-to-ground faults.
\end{abstract}

\section{Introduction}

The single phase-to-ground faults are the most repeated damages in distribution networks $6-35 \mathrm{kV}$. The feature for operation of the medium voltage networks, which are distribution networks in the Russian Federation, consists in that they are operated with insulated or compensated neutral. This conditions low-low fault currents in case of single phase-to-ground fault that doesn't allow using the methods to determine distances to the fault location based on the emergency mode parameters, which are widely used during monitoring of the power transmission lines with voltage of $110 \mathrm{kV}$ and above [1]. Moreover, the distribution networks have large distances and a great number of connections, i.e. they have branched structure.

Implementation of the advanced means and methods of fault location detection, especially during their complex use, provides a significant technical and economic effect conditioned by reduction of power interruptions, prevention of transition of single phase-toground faults into double faults and transient faults into permanent ones, reduction of electric power losses, decrease of labour costs for inspection of overhead line routes and transportation costs.

Currently different topographic methods of fault location detection for overhead lines $6-35 \mathrm{kV}$ are applied $[2,3]$, short circuit indicators being capable to transmit information about actuation via wireless communication channels are used [4], researches on use of the pulse methods (wave [5, 6] and location [7, 8]) are performed.

Use of the fault detection location method in networks 6$35 \mathrm{kV}$ is of considerable interest, as this method: has low error; is remote; can be used for overhead and aerial cable power transmission lines; the line sounding process is not timerelated to the transient process at obligatory line energization (contrary to the wave method), thus the fault location detection can be performed for de-energized line.
The objective of the fault detection location method in the lines without taps is not complex and the fault detection process can be easily automated. Usually overhead lines and cable aerial lines with voltage of $6-35 \mathrm{kV}$ have generally many taps, in this case the fault detection process become complicated [8]. Moreover, for each certain line the optimum parameters of sounding signal shall be selected depending on its design, type and level of electrical interferences being always available in the carrier line link. The simulation modelling with experimental inspection of the local signal propagation via overhead lines and cable aerial lines with voltage of $6-35 \mathrm{kV}$ allows solving the fault detection problem for these lines.

\section{Simulation model}

Modelling of the local signal propagation via overhead power transmission lines was implemented by PSCAD software [9].

As video pulses, which have a wide spectrum, are used as the sounding signal of the location complex, the frequency-dependent models shall be used.

In PSCAD software there is a possibility to model both the overhead lines and the cable lines, thus the cable aerial lines can be modelled combining the sections. The overhead lines (aerial section of the cable aerial line) is implemented based on "Transmission lines" library, and the cable line (cable section) is implemented based on "Cables" library.

The power transmission line can have several inserted cables, taps, different poles and wire grade within separate areas, thus, in the model this line is divided into segments, within the ranges of which the basic parameters of the line segment remain unchanged (Fig. 1).

The basic parameters of the line segment will consists of those parameters, based on which matrices of internal and mutual resistances for wires $\mathrm{Z}$ and conductivity $\mathrm{Y}$ are calculated.

* Corresponding author: Minullin@mail.ru 


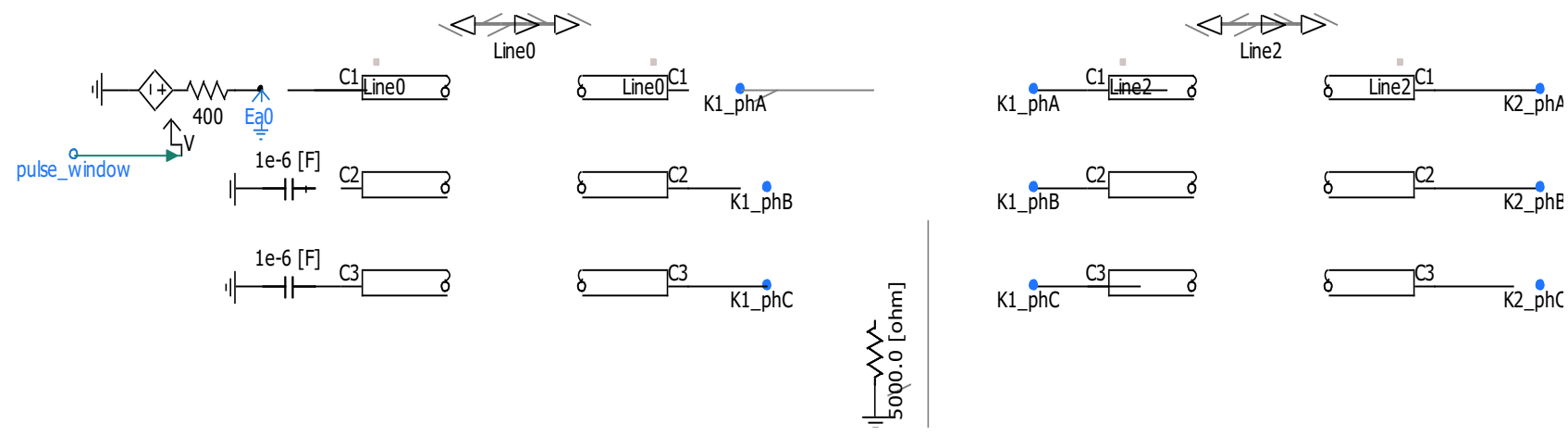

Fig. 1. Segments of Power Transmission Line Model in PSCAD Software

Such parameters include the following for overhead line (overhead section of the cable aerial line): number and arrangement of conductors in space relative to ground, radius and specific resistance of the conductor, specific resistance of the ground, specific magnetic capacity of the ground, amount of deflection. For cable segment specific inductive and magnetic capacity of insulation and insulation layer radius shall be specified additionally. During implementation of inserted cables different cables can be used (three single-phases or one three-phases) with paper-oil insulation or cross-linked polyethylene insulation, this feature can also be considered in the model.

The square-wave generator virtual digital oscilloscope and virtual digital oscilloscope connected at the beginning of the line (Fig. 2) are used as a reflectometer in this simulation model.
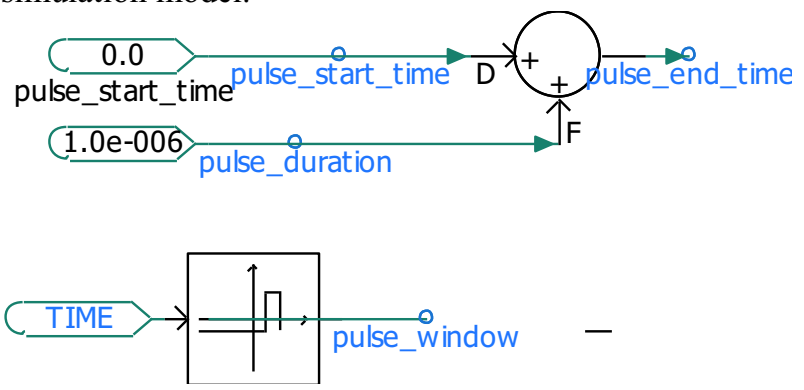

Fig. 2. Square-wave generator in PSCAD software

The following square-wave generator parameters can be specified: output resistance, amplitude, duration and pulse repetition period. The generator output resistance shall match the line wave resistance.

The transient resistance in the area of the fault location detection is mainly active, and its value can be changed from 0 to $5 \mathrm{kOhm}$. Thus faults are simulated by means of artificial discontinuities by connection of active resistance between phase conductor and ground (Fig. 1).

The model descriptions of the situations in the overhead lines upon availability of single phase-to-ground fault were checked by experiments under the laboratory and field conditions.

\section{Model and experimental researches}

The laboratory researches for single phase-to-ground fault detection by the location method were performed using the overhead line dummy with length of $50 \mathrm{~m}$, which wires are attached to the cross beams of the concrete poles via ceramic insulators, wire grade shall be $\mathrm{AC}-70$. The features of the power transmission line sounding and the measurement procedure were considered in the previous publications [7, 8, 10-13].

Experiments were performed in different seasons - in winter (wire snow short circuit) and in summer (wire ground short circuit). The line reflectograms obtained during experimental measurement and while modelling were compared.

Fig. 3 shows the results of single-phase line-to-ground fault research in winter, i.e. snow short circuit.

The parameters detected with reflectometer REYS105R during sounding: positive polarity pulse with amplitude of $U=3.5 \mathrm{~V}$ and duration of $t=0.042 \mu \mathrm{s}$; amplification of $6 \mathrm{~dB}$. REYS-105R was connected to the line via "phase-ground" circuit. Single-phase line-toground fault (snow) was performed with aluminium wire at a distance of $38 \mathrm{~m}$ from its beginning in B point.

Fig. 3, $b$ and Fig. 3, $c$ show reflectograms $U(l)$ of the overhead line under initial condition, moreover, the line ends are opened at B point (under no-load conditions - idling) that is characterized by positive polarity pulse reflecting at this point. The reflected pulse amplitude is slightly greater in the model reflectogram, than in the experimental one. Probably this is conditioned by inaccurate setting of the ground parameters, as analytical calculation of all factors influencing the ground resistance is complicated. Moreover, one of the basic aspects associated with ground simulation is frequency dependence of its specific resistance and dielectric capacity [14].

Fig. 3, $d$ and Fig. 3, e show the line reflectograms at single phase-to-ground fault at $\mathrm{C}$ point generating reflected negative pulse. This pulse is accurately visible in the model reflectogram due to absence of the interferences. The difference method can be used both during automation of the location method and for greater reliability during visual detection of the reflected pulse on the reflectometer screen. For this purpose, initial experimental and model reflectograms of the healthy line shall be subtracted from the similar line reflectograms obtained during single phase-to-ground fault accordingly. The fault location is accurately detected at $38 \mathrm{~m}$ from the line beginning in the form of the first apparent negative pulse with high amplitude in differential reflectograms $\Delta U(l)$ Fig. $3, f, g$. For the experimental reflectogram its amplitude is significantly greater than the amplitudes of the preceding pulses of signal noise component and, thus, it is outlined absolutely certain. 
In case of single phase-to-ground fault while propagating a part of pulse energy reflects from the location of single phase-to-ground fault at $\mathrm{C}$ point, and the other part passes further in the line and reflects from the open end of the line at B point, that is properly shown in reflectogram in Fig. 3, $c$ and Fig. 3, $d$.

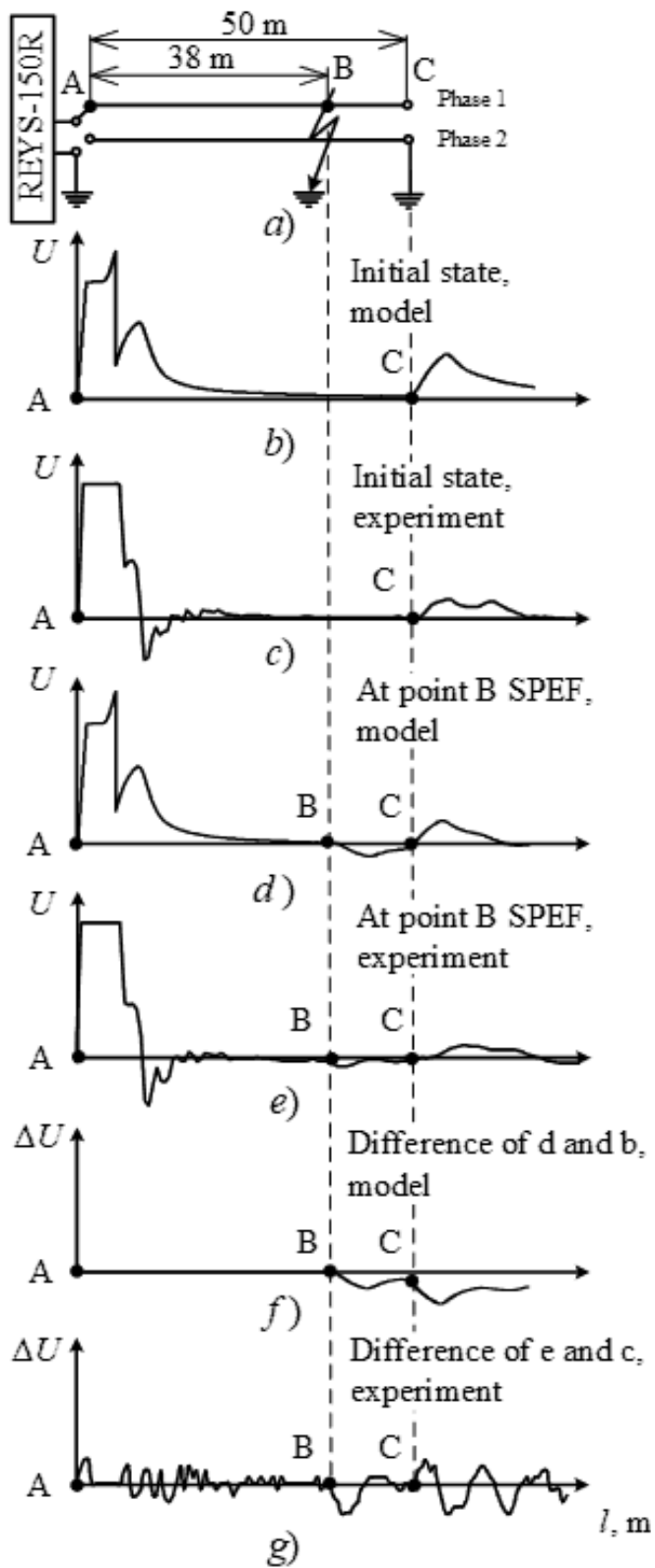

Fig. 3. Scheme of overhead line and model and experimental reflectograms on single phase-to-ground fault detection within winter period: $a$ - reflectometer connecting diagram; $b, c-$ model and experimental reflectograms of the line under initial condition; $d, e$ - model and experimental reflectograms during single phase-to-snow fault; $f, g$ - differential reflectograms

Fig. 4 shows the results of performed measurements in the same line in case of one phase wire ground fault (in summer) at a distance of $38 \mathrm{~m}$ from the line beginning at C point.

The fault locations at a distance of $38 \mathrm{~m}$ from the line beginning were accurately detected by the differential method (Fig. 4, f, g). The reflectograms in Fig. 4 show the same principles in pulse reflection as in Fig. 3. Thereby, when comparing the reflectograms for winter and summer periods, it can be observed, that in summer reflectograms attenuation is increased. It can be explained by increase of deflection amount, thus, influence of the ground on HF signal propagation. In the model this circumstance was considered by reduction in wire suspension height that also impacts on attenuation (Fig. 4, d).

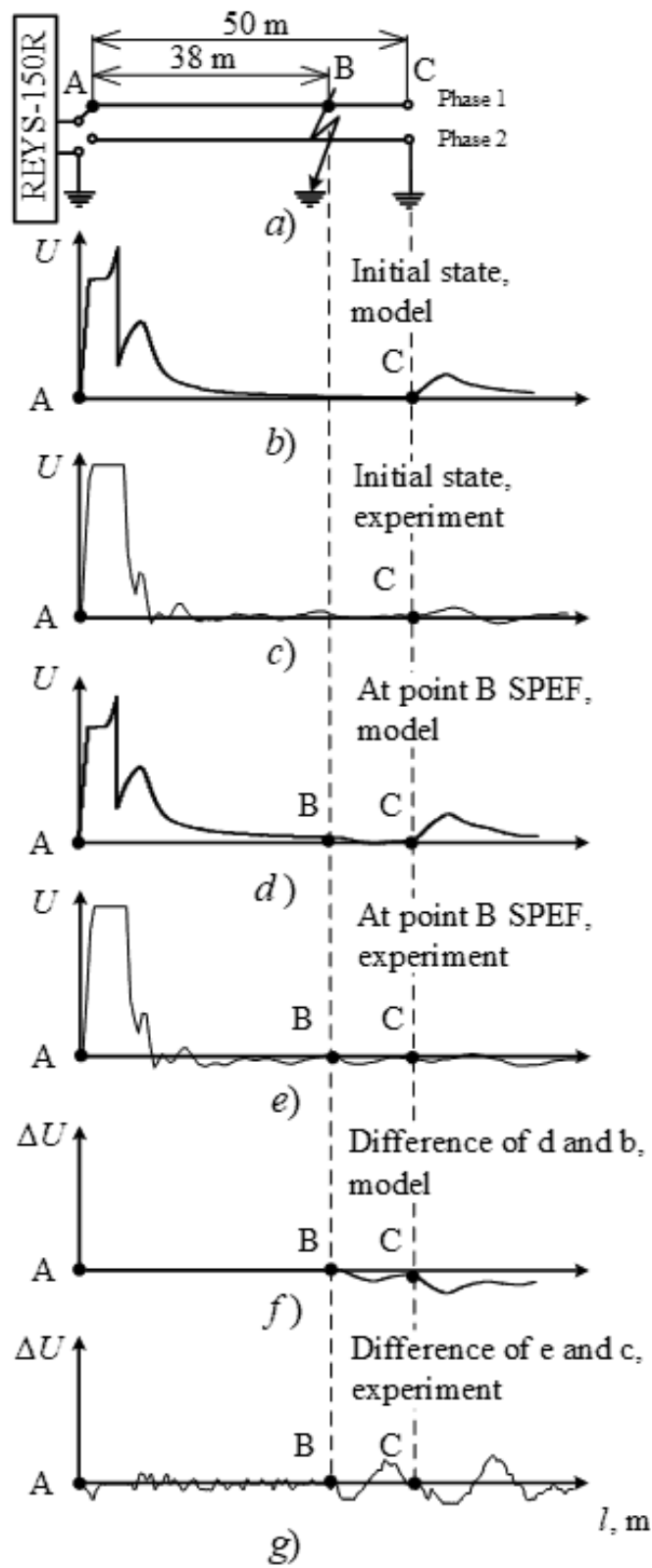

Fig. 4. Scheme of overhead line and model and experimental reflectograms on single phase-to-ground fault detection within summer period: $a$ - reflectometer connecting diagram; $b, c-$ model and experimental reflectograms of the line under initial condition; $d, e$ - model and experimental reflectograms during single phase-to-snow fault; $f, g$ - differential reflectograms

Therefore, it can be said that the reflected pulses at wire single phase-to-snow or phase-to-ground faults don't differ from each other and confidently recognized when using the differential method. 


\section{Fault location detection in lines with taps}

The fault detection location procedure for lines with the linear configuration is rather simple and reliably actual, as shown above. Some complications occur during diagnostics of the line condition with tree-like configuration, which are the major part of the lines in the distribution networks with voltage of $6-35 \mathrm{kV}$.

If the controlled line has a tap, then the fault detected at the certain distance by location sounding can be either in the main line at $\mathrm{E}^{\prime}$ point, or in the tap at $\mathrm{E}^{\prime \prime}$ point, as Fig. 5, a shows.

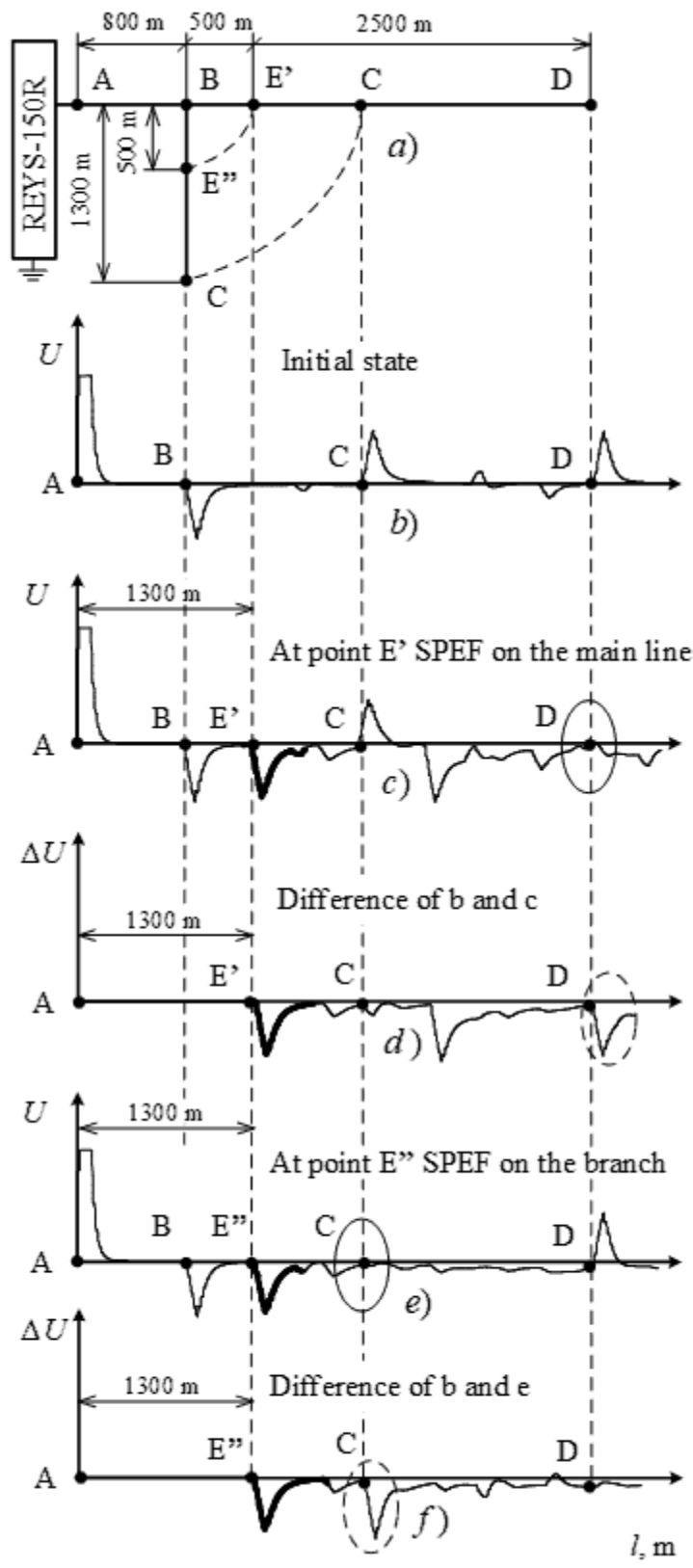

Fig. 5. Diagram of overhead line with tap and model reflectograms at single phase-to-ground fault: $a$ - conventional line diagram; $b$ - initial condition; $c$ - reflectogram at single phase-to-ground fault in main line at $\mathrm{E}^{\prime}$ point; $d$-difference of $c$ and $b$ reflectograms: $e$ - reflectogram at single phase-toground fault in tap at $\mathrm{E}^{\prime \prime}$ point: $f$-difference of $e$ and $b$ reflectograms
The algorithm for elimination of this two-valuedness is based on the main location sounding principle: sounding pulse completely reflects from such large discontinuities of the wire wave resistance $Z \mathrm{w}$ occurring in case of short circuit $(Z \mathrm{w}=0)$ or in case of wire breakage $(Z \mathrm{w}=\infty)$. In this case pulse doesn't certainly propagate further in the line, and the pulse reflected from the line end or the tap end is not generated.

Thus a simple logical analysis of the sounding pulse reflection process allows solving this problem.

If the fault occurs in the main line, then pulse previously reflecting from the line end disappears in the initial reflectogram. If the fault occurs in the tap, then pulse previously reflecting from the tap end disappears. These factors allows expressly determining the fault location in the line. Fig. 5 explains this algorithm in terms of the model interpretation.

The initial reflectogram (Fig. 5, b) corresponds to the line with one tap (Fig. 5, a), which shows positive pulses reflected from the line end at $\mathrm{D}$ point and positive pulse reflected from the tap end at $\mathrm{C}$ point.

In case of fault (for example, short circuit) in the main line, the negative pulse occurs at $E^{\prime}$ point (bold) in the reflectogram given in Fig.5, $c$, and the pulse previously reflected from the line end at $\mathrm{D}$ point disappears (marked in Fig. 5, $c$ as solid oval).

In case of fault in tap, the negative pulse (bold) occurs in the reflectogram (Fig. 5,e) at $\mathrm{E}^{\prime \prime}$ point, and the pulse previously reflected from the tap end at $\mathrm{C}$ point disappears (the location is marked in Fig. 5, $e$ as solid oval).

A distance to the fault location is determined by the differential reflectogram. Moreover, the initial reflectogram is subtracted from the current one, and the fault location is distinctly determined by the first pulse (bold) in the differential reflectogram at a distance of $1300 \mathrm{~m}$ (Fig. 5, $d$, as well as Fig. 5, f).

As a result of subtraction the differential reflectograms in Fig. 5, $d$ and Fig. 5, $f$ show pulses reflected from the fault locations at $\mathrm{C}^{\prime}$ and $\mathrm{C}^{\prime \prime}$ points accordingly (negative, in case of wire short circuit and positive, in case of wire breakage). Besides, if this fault occurs in the main line, then at the line end at D point in Fig. 5, $d$ the reflected pulse designated with dashed oval is shown. If the fault occurs in the tap, then the pulse reflected from the tap end at $\mathrm{C}$ point in Fig. 5, $f$ designated with dashed oval is shown.

Use of the differential reflectograms is an additional source of information about line wire fault location.

The considered procedure can also be successfully used upon availability of the large number of taps in the line. Moreover, the following requirements shall be fulfilled: sufficiency of the resolution capability for location sounding at the certain line length and configuration, i.e. the reflected pulses shall be as short as possible and shall not superimpose on one another in the reflectogram and distinguished separately (that is not always fulfilled in the lines with small length). Thus, when determining the line sounding conditions, the optimum duration of sounding pulses shall be chosen matched with its certain length and configuration.

The described features of differential reflectogram distinction allows sufficiently simple implementation of 
the fault location detection algorithm in the power transmission lines in the automatic mode.

\section{Conclusions}

1. Use of PSCAD software allows developing the simulation model for location signal propagation via the power transmission lines in the distribution networks 6$35 \mathrm{kV}$ in case of single phase-to-ground fault.

2. The results of performed model and experimental researches in case of single phase-to-ground fault show high convergence and adequacy of the model and experimental reflectograms for line $6-35 \mathrm{kV}$ that indicate the representativeness of the developed model.

3. The developed model can efficiently be used in the line of the operating distribution networks $6-35 \mathrm{kV}$ during their diagnostics and constant monitoring.

\section{References}

1. V.A. Kasimov, R.G. Minullin, Yu.V. Piskovatsky, E.Yu. Abdullazyanov, Elektrosvyaz, 4, p. 65-71 (2019)

2. E.A. Arzhannikov, A.M. Zhukhin Methods and Devices for Fault Location Detection in Power Transmission Lines, M.: Science-Technical Company “Energopress”, 87 p. (1998)

3. B.K. Maksimov, Ya.L. Artsishevsky, E. Lkhamsuren, Relay Protection and Automation, 3 (28), p. 27-32 (2017)

4. K.V. Tarasov, Electric Energy: Transmission and Distribution, 4, p. 73-74 (2014)

5. A.L. Kulikov, A.A. Loskutov, P.S. Pelevin, Electricity, 3, p. 11-17 (2018)
6. R.G. Khuzyashev, S.M. Tukayev, I.L. Kuzmin, Energy Security and Energy Saving, 6, p. 5-17 (2018)

7. R.G. Minullin, I.Sh. Fardiyev, D.F. Gubayev, O.I. Karpenko, E.V. Zakamsky, Electrical Engineering, 5, p. 2-10 (2006)

8. R.G. Minullin, I.Sh. Fardiyev, News of Higher Educational Institutions. Problems of Power Engineering, 5-6, p. 43-47 (2004)

9. Transient Analysis for PSCAD Power System Simulation: EMTDC user's guide, 4.6. Manitoba HVDC Research Centre, a division of Manitoba Hydro International Ltd.

10. R.G. Minullin, E.V. Zakamsky Fault Location Detection in Electric Networks with Voltage of 6-35 $k V$ by Pulse Method: Materials of Reports of the Russian National Symposium on Power Engineering. Kazan: Kazan State Power Engineering University, 2, p. 62-64 (2001)

11. R.G. Minullin, E.V. Zakamsky, V.V. Andreev, Electrical Engineering, 10, p. 39-44 (2003)

12. R.G. Minullin, E.V. Zakamsky Fault Detection in Distribution Networks by Location Method. Kazan: Research Centre Energopress LLC, 127 p. (2004)

13. I.Sh. Fardiyev, R.G. Minullin, E.V. Zakamsky, V.V. Andreev, D.F. Gubayev, News of Higher Educational Institutions. Problems of Power Engineering, 7-8, p. 41-49 (2004)

14. C.M. Portela, J.B. Gertrudes, M.C. Tavares, F.J. Pissolato, Electric Power Systems Research, 76, p. 907-915 (2006) 